\title{
Experimental Murine Candidiasis: Cell-Mediated Immunity After Cutaneous Challenge
}

\author{
STEPHEN A. MOSER,' ${ }^{*}$ JUDITH E. DOMER, ${ }^{1}$ AND FRANCES J. MATHER ${ }^{2}$
}

Department of Microbiology and Immunology, School of Medicine, ${ }^{1}$ and Department of Biostatistics and Epidemiology, School of Public Health and Tropical Medicine, ${ }^{2}$ Tulane University, New Orleans, Louisiana 70112

Male CBA/J mice, sensitized by cutaneous inoculation with viable Candida albicans blastospores, were used to study in vivo and in vitro cellular immune responses. Three antigens of $C$. albicans, viz., a cell wall glycoprotein (GP), a membrane extract (ppt-HEX), and soluble cytoplasmic substances (SCS), were used in vitro in a lymphocyte stimulation assay, whereas the GP and ppt-HEX were used in vivo to detect delayed hypersensitivity by the footpad assay. Delayed hypersensitivity to GP and ppt-HEX was transferred from sensitized donors to naive recipients with peritoneal exudate cells and not with serum. Moreover, the transfer of the reactivity to ppt-HEX was abrogated by the prior treatment of the transfer suspension with anti-theta 1.2 serum and complement. The in vitro lymphocyte response to GP and ppt-HEX correlated qualitatively with the in vivo responses. SCS, a preparation shown to be ineffective in vivo previously, did stimulate lymphocytes from sensitized animals in vitro. The in vitro response to Candida antigens, as well as phytohemagglutinin, was abolished by treatment of the lymphocyte suspension with anti-thymocyte 1.2 serum before assay, whereas anti-immunoglobulin serum had less effect on these responses. The in vivo and in vitro reactivity to the Candida antigens, therefore, was dependent upon viable T-lymphocytes. Preliminary specificity studies were carried out in the lymphocyte stimulation assay, using lymphocytes from mice infected with $C$. albicans tested against ppt-HEX preparations extracted from two other species of Candida, $C$. tropicalis and $C$. guillermondii, and from two other pathogenic yeast forms, Histoplasma capsulatum and Blastomyces dermatitidis. Significant cross-reactivity was observed with $C$. tropicalis only, a species which is known to be serologically related to $C$. albicans.

Since Candida albicans is a common commensal of humans (6) and most normal individuals routinely have demonstrable immune responses to it, Candida antigens are usually used in assays of cellular immunity when the general immune status of an individual is in question. The same assays, e.g., skin testing, lymphocyte stimulation, and assays for macrophage inhibitory factor, are also used to evaluate immune response during episodes of candidiasis $(2,11)$. Commercial extracts of Candida are frequently used in these assays, but when using such extracts one is faced with two problems. First, little is known of their preparation and composition; second, the preparation most often used is preserved with phenol, which must be removed before use with viable cells. Standardization of the conditions for the in vitro assays, then, is difficult, but several investigators have made attempts to do so $(1,11)$. Other investigators have simply used one commercial preparation for in vivo testing and a different one for in vitro assays $(2,29)$.
In this laboratory, we have been attempting to prepare extracts of Candida which can be standardized and defined chemically and then used in both in vivo and in vitro assays for cellular immunity. In a previous publication (9), we reported success in demonstrating delayed hypersensitivity in vivo in a murine model of candidiasis, using two different extracts of $\mathrm{Can}$ dida. Both extracts were prepared from subcellular fractions of the organism; one was a glycoprotein (GP) extracted from cell walls with ethylenediamine, and the other was a proteinrich preparation of the cellular membranes (pptHEX), the proteins having been precipitated with ammonium sulfate from an extract obtained with hot buffered saline. The in vivo responses to ppt-HEX were shown to be cell mediated in that the transfer of delayed hypersensitivity from sensitized to unsensitized mice was accomplished with immune peritoneal exudate cells (PEC) and not serum. In this paper, we present the results of additional studies with these two antigens, including the transfer of 
delayed hypersensitivity to GP, demonstration of the dependence on T-lymphocytes of passive transfer of delayed hypersensitivity to ppt-HEX, and demonstration that both antigens were effective in stimulating sensitized lymphocytes in vitro. A third subcellular preparation, soluble cytoplasmic substances (SCS), was also successfully tested in the in vitro assay.

\section{MATERIALS AND METHODS}

Culture and fractionation procedures. C. albicans B311, originally obtained from $\mathrm{H}$. Hasenclever, was maintained on modified Sabouraud dextrose agar slants (Difco Laboratories, Detroit, Mich.) at $4^{\circ} \mathrm{C}$ with monthly transfers. Growth conditions and preparation of viable cells for cutaneous inoculation and antigen isolation have been previously described in detail (9). To prepare subcellular components, washed blastospores suspended in tris(hydroxymethyl)aminomethane buffer were disrupted by ballistic action in a Braun cell homogenizer, and the homogenate was separated into cell walls, membrane mitochondria (MM), and SCS as described previously $(8,9)$. The washed cell walls were extracted for GP with ethylenediamine according to the method of Korn and Northcote (19). The water-soluble GP fraction was recovered from ethylenediamine by methanol precipitation, dialyzed against distilled water, and lyophilized. The MM fraction was dialyzed against distilled water, lyophilized, and extracted with phosphatebuffered saline, $\mathrm{pH} 7.4$, for $1 \mathrm{~h}$ at $50^{\circ} \mathrm{C}(14)$. Proteins were precipitated from the extract with ammonium sulfate, $100 \%$ saturation, and the precipitate was redissolved in NPS before dialysis against the same solvent. Protein content was determined by the method of Lowry et al. (21), using a bovine serum albumin standard. The extract was then diluted to the appropriate concentration and stored at $-20^{\circ} \mathrm{C}$ until used. In addition to the extraction of MM from C. albicans B311, the MM fractions of $C$. tropicalis 53 and C. guillermondii $2309(\mathrm{H})$ and the yeast phases of Histoplasma capsulatum SwA and Blastomyces dermatidis 3849 were extracted by the same procedure. The heat-extracted precipitated extracts will hereafter be referred to as ppt-HEX, preceded by the strain from which that extract was derived. The SCS was dialyzed against distilled water, lyophilized, and stored in vacuo over desiccant. Two commercial extracts of $C$. albicans were purchased from Hollister-Stier (Spokane, Wash.): Dermatophytin $O$ and $C$. albicans extract with $50 \%$ glycerine.

Animal sensitization. Ten- to 12 -week-old male CBA/J mice (Jackson Laboratories, Bar Harbor, Maine) were used throughout these experiments. Mice were sensitized by one or two intracutaneous inoculations of $1.0 \times 10^{6}$ viable $C$. albicans B311 blastospores suspended in $0.05 \mathrm{ml}$ of NPS (14). When two inoculations were used, the interval between the first and second inoculations was 2 weeks.

Passive transfer and anti-theta treatment. PEC were induced by the intraperitoneal injection of casein (22) into 20 infected or uninfected mice $48 \mathrm{~h}$ before cell harvest. Cells from infected mice were harvested 7 days after the second cutaneous inocula- tion of viable $C$. albicans by washing the peritoneal cavity with approximately $5 \mathrm{ml}$ of cold RPMI 1640 (GIBCO, Grand Island, N.Y.) supplemented with 10 Units of preservative-free heparin (GIBCO) per ml and $1 \%$ (vol/vol) heat-inactivated normal horse serum (GIBCO). Just before cell harvest, mice were bled by cardiac puncture and serum was obtained. The ratio of donor mice to recipients was $2: 1$ so that sera ( 0.3 to $0.4 \mathrm{ml})$ or washed PEC $(0.5 \mathrm{ml})$ from two donor mice were pooled and injected intravenously into one normal recipient animal.

In selected instances, PEC suspensions were treated with anti-theta serum before transfer. Cells to be treated were centrifuged at $160 \times g$ at $4^{\circ} \mathrm{C}$ for $10 \mathrm{~min}$, the supernatant was aspirated, and the pellet was resuspended in either antitheta (anti-Thy 1.2) $1.2 \mathrm{se}$ rum $\left(\mathrm{AKR} / \mathrm{J}\right.$ anti- $\left.\mathrm{C}_{3} \mathrm{H} / \mathrm{HeJ}\right)$ or mock anti-theta serum (AKR/Cum anti- $\mathrm{C}_{3} \mathrm{H} / \mathrm{HeJ}$ ) (Litton Bionetics, Kensington, Md.) diluted 1:10 in RPMI 1640. Each suspension was incubated on ice for $1 \mathrm{~h}$. Guinea pig serum (GIBCO) absorbed with agarose (L'Industrie Biologique Française S.A., Gennevilliers, France) was added to a final concentration of 1:6 as a source of complement (5), and the cells were incubated for an additional $45 \mathrm{~min}$ at $37^{\circ} \mathrm{C}$ in an atmosphere of $5 \% \mathrm{CO}_{2}$ in air. The treated cells were then washed before transfer and resuspended in fresh RPMI 1640. Mice were footpad tested (14) $18 \mathrm{~h}$ after transfer of cells or serum with either GP $(30 \mu \mathrm{g}$, total weight per test dose) or ppt-HEX (20 $\mu \mathrm{g}$ of protein per test dose). The test antigens were prepared so that the appropriate concentration was contained in $0.02 \mathrm{ml}$ of NPS which was delivered through a 30-gauge needle attached to a micrometer syringe (Gilson). Each foot was measured with a Schnelltäster calipers (H. Kröplein $\mathrm{GmbH}$, Schluchtern, Federal Republic of Germany) before and at $15 \mathrm{~min}$ and $4,7,24$, and $48 \mathrm{~h}$ after antigen injection. The mean net increase in footpad thickness for each group was determined by subtraction of preand postinjection measurements. The groups were randomized, and their identity was unknown to the individual measuring the reactions.

Lymphocyte stimulation. Inguinal lymph nodes draining the site of cutaneous inoculation with $C$. albicans blastospores were excised from three to five mice per group and pooled, and a single-cell suspension was prepared by teasing them apart in cold RPMI 1640 containing $25 \mathrm{mM} \mathrm{N}$-2-hydroxyethylpiperazine$N^{\prime}$-2-ethanesulfonic acid (HEPES; GIBCO) supplemented with $20 \mathrm{mM}$ L-glutamine, $100 \mathrm{U}$ of penicillin and $100 \mu \mathrm{g}$ of streptomycin per $\mathrm{ml}, 5 \%$ (vol/vol) heatinactivated normal pooled horse serum (GIBCO), and $5 \times 10^{-5}$ M 2-mercaptoethanol (3) (Calbiochem, La Jolla, Calif.). After filtering through sterile gauze, the cells were washed in complete medium and resuspended to a concentration of $2.5 \times 10^{6}$ viable cells per $\mathrm{ml}$ as determined by hemocytometer counts of cells stained with trypan blue (GIBCO). Microcultures were set up in flat-bottom microtiter trays (Microtest II, Falcon Plastics, Oxnard, Calif.) by delivering $0.1 \mathrm{ml}$ of cells $\left(2.5 \times 10^{5}\right.$ per well $)$ and $0.1 \mathrm{ml}$ of complete medium alone or complete medium containing the appropriate concentrations of antigen or mitogen to each well. The mitogens used were purified phytohemagglutinin (PHA) (Wellcome Reagents, Ltd., Beck- 
enham, England) and Salmonella typhosa 0901 lipopolysaccharide B (LPS) (Difco). The antigens used were GP, ppt-HEX, and SCS from C. albicans. All conditions were prepared in triplicate, and trays were incubated at $37^{\circ} \mathrm{C}$ in a humid atmosphere of $5 \% \mathrm{CO}_{2}$ in air. Eighteen hours before harvesting with a MASH II unit (Microbiological Associates, Bethesda, Md.), each well was pulsed with $10 \mu \mathrm{l}$ of NPS containing 1 $\mu \mathrm{Ci}$ of $\left[\right.$ methyl $\left.-{ }^{3} \mathrm{H}\right]$ thymidine (specific activity, $6.7 \mathrm{Ci}$ / mmol; New England Nuclear Corp., Boston, Mass.). Mitogens were harvested on the 3rd day of incubation, and antigens were harvested on the 4 th day of incubation. After drying at $100^{\circ} \mathrm{C}$ for $20 \mathrm{~min}$, the glass fiber disks were punched out into plastic liquid scintillation vials (New England Nuclear), and $10 \mathrm{ml}$ of liquid scintillation solution containing $3.66 \mathrm{~g}$ of 2,5diphenyloxazole (PPO; New England Nuclear) and $0.07 \mathrm{~g}$ of $p$-bis-( $O$-methylstyrl)-benzene (New England Nuclear) per liter of scintillation-grade toluene (J. T. Baker Chemical Co., Phillipsburg, N. J.) was added. Samples were counted in a Beckman LS250 for a minimum of 10 min or 10,000 counts. Results were expressed either as ratios of experimental to control or as experimental minus control. Where indicated, lymph node cell suspensions were separated on nylon wool columns as described by Julius et al. (18). Cell suspensions were applied to preconditioned columns in $2 \mathrm{ml}$ of warm $\left(37^{\circ} \mathrm{C}\right) \mathrm{RPMI} 1640$ supplemented with $25 \mathrm{mM}$ HEPES, $100 \mathrm{U}$ of penicillin and $100 \mu \mathrm{g}$ of streptomycin per $\mathrm{ml}$, and $5 \%$ (vol/vol) heat-inactivated pooled fetal bovine serum (GIBCO). Cells were washed into the column with $1 \mathrm{ml}$ of warm medium and incubated for $45 \mathrm{~min}$ at $37^{\circ} \mathrm{C}$. Nonadherent cells were washed out slowly with $25 \mathrm{ml}$ of warm medium, recovered by centrifugation, resuspended in a minimal volume for total and viable counts (trypan blue exclusion), and diluted to $2.5 \times 10^{6}$ viable cells per ml. Unseparated cells from the same lymph node pool were reserved on ice during the column separation, and nylon wool-nonadherent cells and unseparated cells were assayed simultaneously by the technique described above.

In selected experiments, lymph node cells were treated with anti-Thy 1.2 or anti-immunoglobulin antiserum before the lymphocyte stimulation assay. Anti-Thy 1.2 treatment was carried out as described above, and the final preparation for assay was either a suspension of cells in the original volume or a suspension readjusted on the basis of viability assay to $2.5 \times 10^{6}$ viable cells per $\mathrm{ml}$. Anti-immunoglobulin treatment was done with rabbit anti-mouse $7 \mathrm{~S}$ globulin (Nutritional Biochemicals Corp., Cleveland, Ohio), using normal rabbit serum (GIBCO) as the control. Each was diluted 1:3 in RPMI 1640, and complement was added as described for anti-theta treatment. All cells treated with anti-immunoglobulin were resuspended to $2.5 \times 10^{6}$ viable cells per $\mathrm{ml}$.

Statistical analyses. The data were analyzed by methods described in Winer (32), using the BMDP (7) computer package with a DEC-20 computer. In all cases the $\log _{10}$ of responses was analyzed as a variancestabilizing mechanism.

\section{RESULTS}

Passive transfer of footpad reactivity to
GP and ppt-HEX. Results of our attempts to passively transfer the footpad response to GP with untreated PEC and serum from infected and uninfected mice are summarized in Fig. 1. The only two groups of mice in which delayed hypersensitivity responses were detected were the infected control animals and the recipients of PEC from infected donors. The level of response in the recipients of immune cells was about one-half of that observed in infected controls.

Since the PEC suspension was a mixed population consisting of approximately $58 \%$ polymorphonuclear leukocytes, $30 \%$ macrophages, and only $12 \%$ lymphocytes as determined from Wright-stained smears, attempts were made to demonstrate that the reactivity transferred to the ppt-HEX was dependent upon T-lympho-

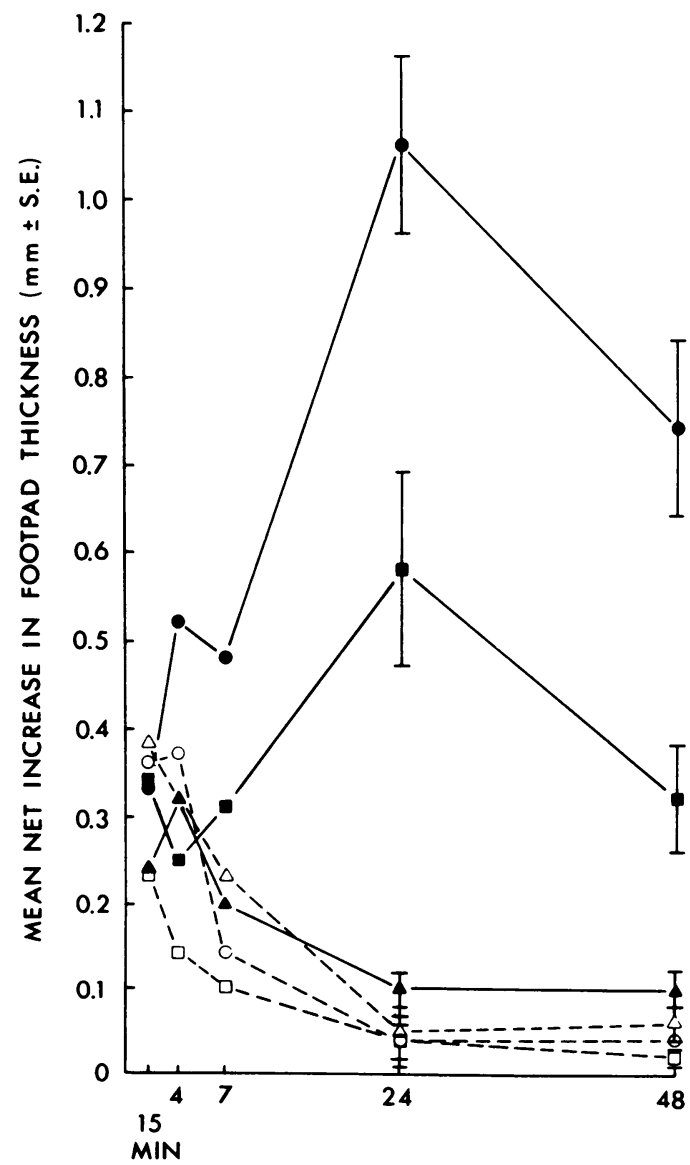

HOURS

Fig. 1. Footpad responses to $30 \mu \mathrm{g}$ of $G P$ of $C$. albicans in infected control mice (O), recipients of PEC from infected donors $(\square)$ or uninfected donors $(\Delta)$, recipients of serum from infected donors $(\square)$ or uninfected donors $(\triangle)$, and uninfected control mice (O). 
cytes. Therefore, PEC were harvested from infected animals 7 days after a second cutaneous inoculation of viable $C$. albicans blastospores and were treated with anti-Thy 1.2 or mock antitheta before injection into naive animals and footpad testing with ppt-HEX. Controls included unmanipulated mice and infected mice. The cell suspensions treated with the anti-Thy 1.2 serum were no longer able to transfer delayed hypersensitivity, whereas those treated with mock anti-theta remained effective (Fig. 2).

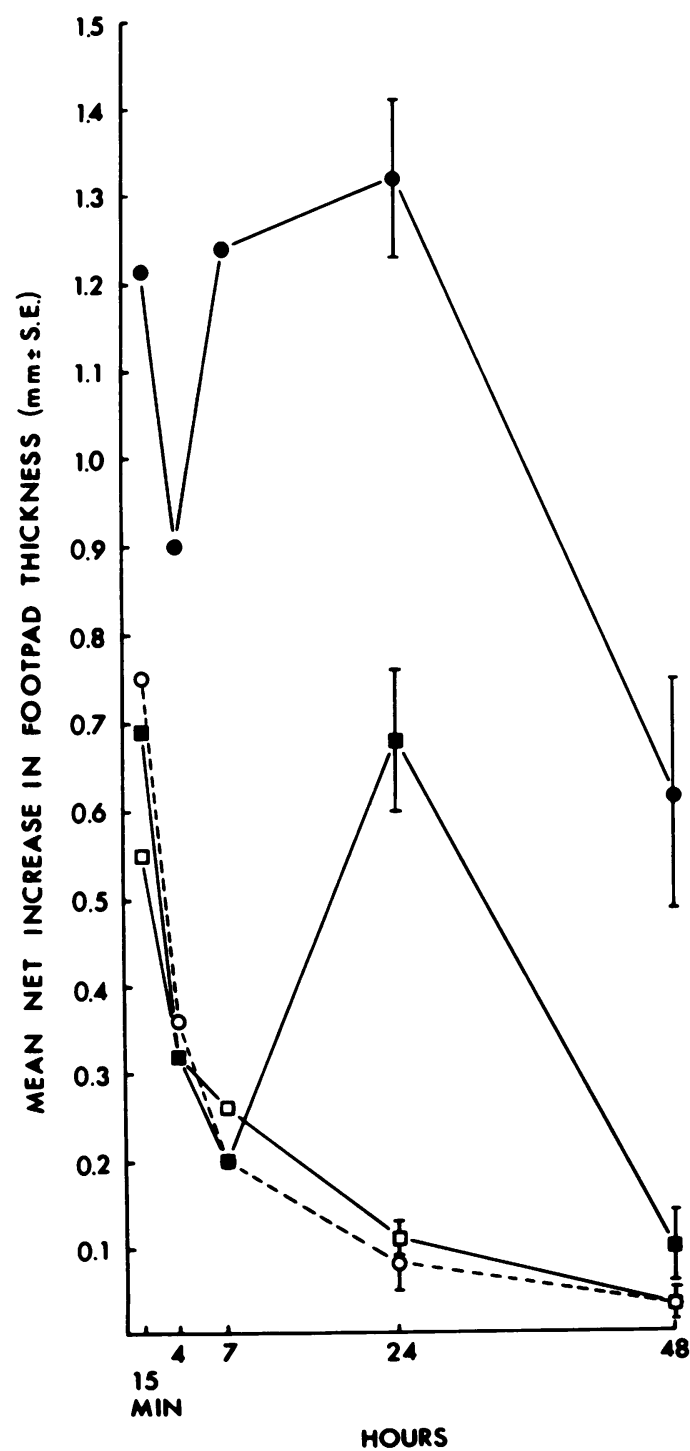

Fig. 2. Footpad responses to $20 \mu \mathrm{g}$ of protein ppt$H E X$ of $C$. albicans in infected mice (O), uninfected mice $(O)$, and recipients of $P E C$ from infected donors treated with either anti-Thy 1.2 ( $(\square)$ or mock antitheta $(\square)$ sera.
Lymphocyte stimulation with unseparated lymph node cells and $C$. albicans antigens. Lymph node cells from mice which had been inoculated once or twice cutaneously with viable $C$. albicans blastospores 3,7 , or 14 days before sacrifice were tested in an in vitro stimulation assay with three subcellular preparations from C. albicans (GP, ppt-HEX, and SCS) as well as with two mitogens (PHA and LPS). The concentrations of antigens and mitogens resulting in maximum stimulation were determined in preliminary experiments. Optimal concentrations per well were 20,200 , and $100 \mu \mathrm{g}$ for pptHEX, GP, and SCS, respectively, and 0.05 and $50 \mu \mathrm{g}$ for PHA and LPS, respectively. When cells were plated onto Sabouraud dextrose agar, we never detected contamination of the lymph node cell suspensions with viable $C$. albicans.

All three $C$. albicans antigens were effective in stimulating lymphocytes from cutaneously infected mice during the course of the experiment (Fig. 3). Both ppt-HEX and SCS stimulated in vitro proliferation to a greater degree than did GP; however, responses to all three antigens on day 3 by mice infected twice cutaneously and day 7 by mice infected once cutaneously were not significantly different $(P>$ $0.05)$. The level of stimulation at 3 days with cells from once- or twice-infected animals was low yet significant $(P<0.05)$. In once-infected animals, this level increased on day 7 and then decreased on day 14 . Although the mean values for ppt-HEX and SCS on day 14 were lower than those on day 7 for animals infected once, this drop was not statistically significant. Unlike mice infected once, the responses to ppt-HEX and SCS in animals infected twice rose from day 3 to day 7 and continued to increase significantly (SCS) or remained at the same level (ppt-HEX). The response to GP by animals infected twice was no different on day 3,7 , or 14 . In addition, when the responses to each antigen of mice infected once or twice were compared on a particular day, a significant difference $(P<0.05)$ was found only on day 7 , when cells from mice infected once responded to a greater degree than cells from animals infected twice. This relationship was not consistent from experiment to experiment, however, and more often there was little difference in the level of reactivity between animals infected once or twice when compared on day 7. For example, the data presented in Fig. 5 to illustrate a different point are based on studies of animals 7 days after one or two cutaneous inoculations with viable $C$. albicans as well, and the open bars represent unseparated cells such as those used in the experiment depicted in Fig. 3. The levels of reactivity of mice infected once or twice were very similar (see Fig. 

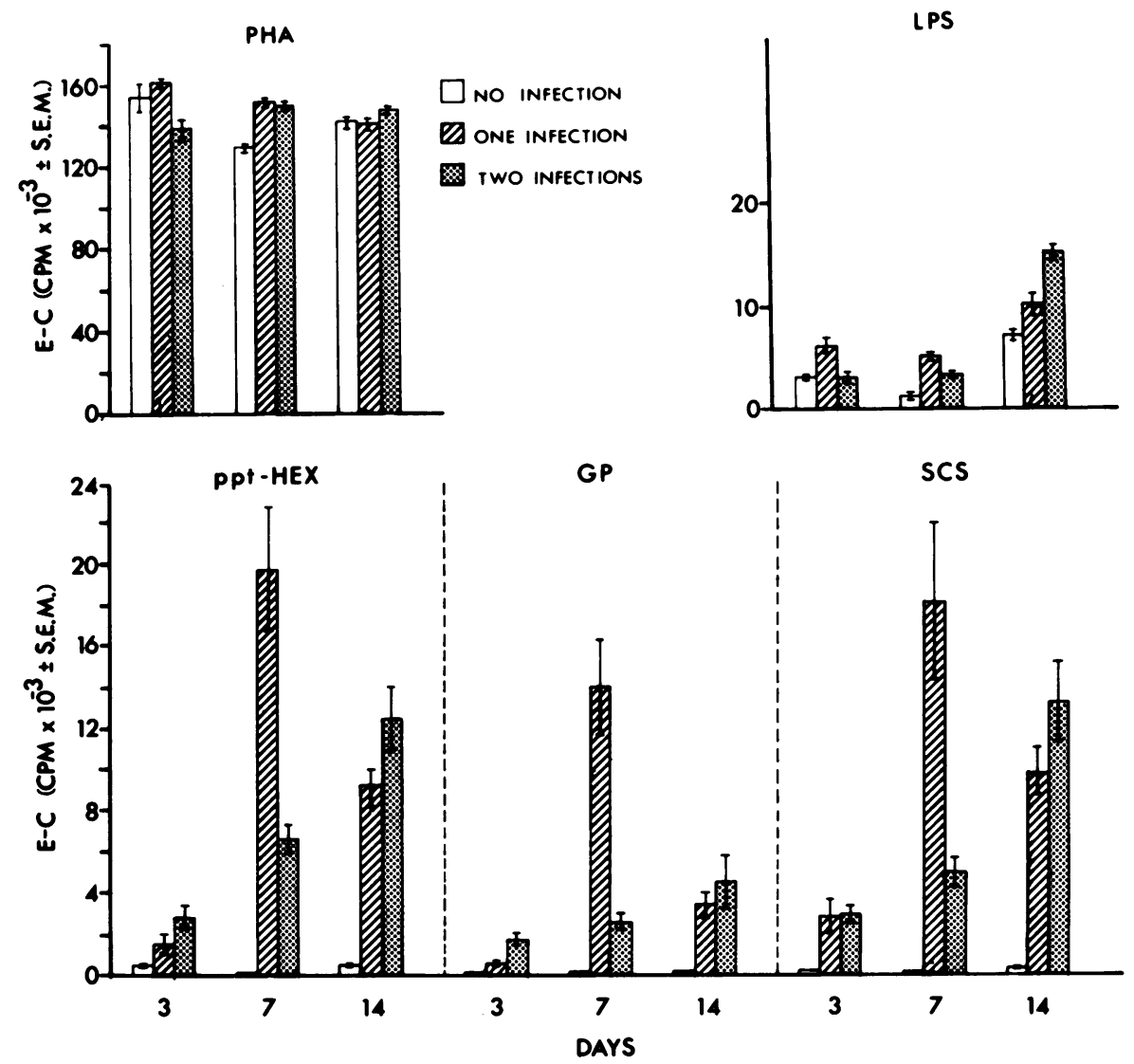

Fig. 3. In vitro lymphocyte proliferation in response to mitogens or C. albicans antigens, using unseparated inguinal lymph node cells from uninfected mice or from mice infected cutaneously once or twice 3,7 , or 14 days before lymph node removal.

5). The response of lymphocytes from the same experimental animals to PHA was similar whether the animals had been infected or were uninfected. LPS responses were much lower and more variable, however, with cells from mice infected once responding to a somewhat greater degree than uninfected mice when tested on days 3 and 7. Cells from mice infected twice responded to a greater degree than those from uninfected mice at both the 7- and 14-day observation periods.

Separate groups of animals infected at the same time as the animals whose lymphocytes were used in the above stimulation assays were footpad tested with GP and ppt-HEX of $C$. albicans 7 and 14 days after one or two infections for comparison with the stimulation results (Table 1). Only 24-h responses are presented, but the temporal development of the reactions was similar to that depicted in Fig. 1 and 2. The level of delayed hypersensitivity to each antigen was greater 7 or 14 days after two cutaneous
TABLE 1. Mean net increase in footpad thickness 24 $h$ after injection of $20 \mu g$ of protein of $C$. albicans ppt-HEX or $30 \mu \mathrm{g}$ (total weight) of GP into mice infected once or twice cutaneously with $10^{6}$ viable $C$. albicans blastospores

\begin{tabular}{l|c|c|c|c}
\hline \multirow{2}{*}{$\begin{array}{c}\text { No. of } \\
\text { infec- }\end{array}$} & \multicolumn{3}{|c|}{ Increase in footpad thickness (mm) } \\
\cline { 2 - 5 } tions & \multicolumn{2}{|c|}{ ppt-HEX } & \multicolumn{2}{c}{ GP } \\
\cline { 2 - 5 } & 7 Days $^{a}$ & 14 Days & 7 Days & 14 Days \\
\hline None & $0.04(0.02)^{b}$ & $0.07(0.03)$ & $0.15(0.04)$ & $0.06(0.02)$ \\
1 & $0.46(0.09)$ & $0.48(0.08)$ & $0.50(0.07)$ & $0.69(0.12)$ \\
2 & $1.54(0.10)$ & $0.86(0.11)$ & $1.72(0.08)$ & $1.06(0.08)$ \\
\hline
\end{tabular}

${ }^{a}$ Days after one or two cutaneous inoculations.

${ }^{b}$ Mean (standard error of the mean).

inoculations of $C$. albicans than it was after one inoculation. The levels of reactivity in response to ppt-HEX at both 7 and 14 days after a single cutaneous inoculation with Candida, however, were similar, whereas that in response to GP was slightly greater at 14 days. Responses to both antigens in animals infected twice was sig- 
nificantly reduced $(P<0.05)$ over that observed at 7 days.

Several attempts were made to stimulate with commercial antigens lymph node cells from animals infected with $C$. albicans. Initially, attempts were made to dialyze the commercial preparations to remove preservatives, but that resulted in the removal of Lowry-reactive material such that the preparations could not be standardized. We then decided to attempt to dilute the commercial preparations to minimize the effect of preservative as others have done (15). Two extracts, obtained from HollisterStier, were used: Dermatophytin 0 , preserved with phenol, and C. albicans extract, preserved with $50 \%$ glycerine. Both extracts were toxic at a 1:100 dilution and not stimulatory at higher dilutions (data not shown).

Lymphocyte stimulation with unseparated lymph node cells and heterologous antigens. Attempts were made to determine whether antigens similar to those extracted from C. albicans could be extracted from other species of Candida or from pathogenic yeast forms. The data with ppt-HEX fractions obtained from a single strain each of $C$. tropicalis, $C$. guillermondii, $H$. capsulatum, and $B$. dermatitidis are summarized in Table 2. Lymphocytes were obtained from mice infected twice cutaneously, the second inoculation having been given 7 days before lymph node removal. None of the extracts stimulated cells from uninfected animals, and
ppt-HEX fractions of only $C$. albicans and $C$. tropicalis were stimulatory to cells from infected animals. The extract from $B$. dermatitidis appeared to be toxic, particularly at the 20 - and 40 $\mu \mathrm{g}$ levels. Although the $C$. guillermondii extract at $10 \mu \mathrm{g}$ per well resulted in a response with cells from infected animals that was statistically greater than that from uninfected cells $(P<$ $0.05)$, we arbitrarily select a ratio of 3.0 as the least for significance.

Lymphocyte stimulation with nylon wool-separated lymph node cells and cells treated with antisera and complement. In an attempt to determine the class of lymphocyte in the lymph node suspension responsible for in vitro stimulation in response to Candida antigens, lymphocyte suspensions were treated in two ways. First, suspensions of lymphocytes from mice infected cutaneously twice before lymph node harvest were separated by means of nylon wool and tested before and after separation. Second, unseparated lymphocyte suspensions were treated with anti-Thy 1.2 serum, mock anti-theta serum, anti-mouse immunoglobulin (7S) serum, or normal rabbit serum before being placed in the lymphocyte assay.

In preliminary experiments comparing unseparated, nylon wool-nonadherent and nylon wooladherent cells, the adherent cell population was significantly contaminated by PHA-reactive cells, and we therefore chose to eliminate the adherent cells from further study. Nylon wool

TABLE 2. Lymphocyte stimulation of lymph node cells from mice 7 days after a second cutaneous inoculation with C. albicans, using ppt-HEX antigens extracted from several different yeasts

\begin{tabular}{lccccc}
\hline $\begin{array}{c}\text { Antigen or mito- } \\
\text { gen }\end{array}$ & Concn $(\mu \mathrm{g} /$ well) & Uninfected cpm & E/C & Infected cpm & E/C \\
\hline None & & $320(18)$ & 1.0 & $520(30)$ & 1.0 \\
C. albicans & 10 & $375(40)$ & 1.2 & $7,553(2,266)^{c}$ & 14.1 \\
& 20 & $417(43)$ & 1.3 & $7,660(1,939)^{c}$ & 14.7 \\
C. tropicalis & 40 & $271(66)$ & 0.8 & $3,561(927)^{c}$ & 6.8 \\
& 10 & $499(50)$ & 1.6 & $3,801(1,150)^{c}$ & 7.3 \\
C. guillermondii & 20 & $449(44)$ & 1.4 & $4,839(1,278)^{c}$ & 9.3 \\
& 10 & $416(99)$ & 1.3 & $4,860(1,981)^{c}$ & 9.3 \\
H. capsulatum & 20 & $396(42)$ & 1.2 & $1,244(294)^{c}$ & 2.4 \\
& 40 & $442(37)$ & 1.4 & $911(206)$ & 1.8 \\
B. dermatitidis & 10 & $375(36)$ & 0.5 & $208(17)$ & 0.4 \\
& 20 & $433(70)$ & 1.2 & $602(68)$ & 1.2 \\
None & 10 & $307(53)$ & 1.4 & $526(80)$ & 1.0 \\
PHA & 20 & $242(21)$ & 1.0 & $334(57)$ & 0.6 \\
LPS & 40 & $110(35)$ & 0.3 & $368(57)$ & 0.7 \\
\hline
\end{tabular}

${ }^{a}$ Mean of three pools, each pool consisting of three mice (standard error of the mean).

${ }^{b}$ Ratio of experimental to control.

${ }^{c}$ Value significantly greater $(P<0.05)$ than those obtained with cells from uninfected mice. 
separation of the lymphocytes was effective in removing LPS-reactive cells (Fig. 4), inasmuch as the nonadherent cells from the column effluent had a greatly reduced capacity to respond to LPS. In the case of PHA stimulation (Fig. 4), counts were only slightly decreased in uninfected mice or were unchanged. Nylon wool-nonadherent cells, although essentially unresponsive to

LIPOPOLYSACCHARIDE

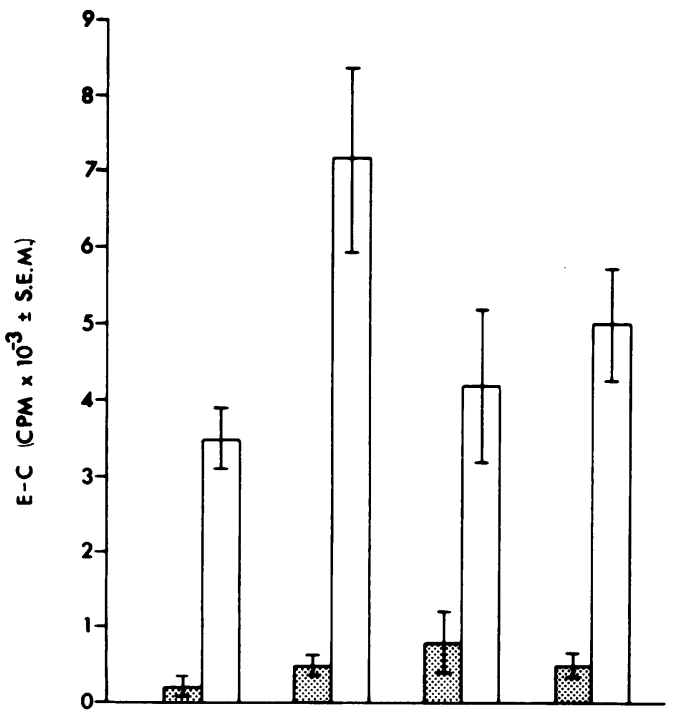

PHYTOHEMAGGLUTININ

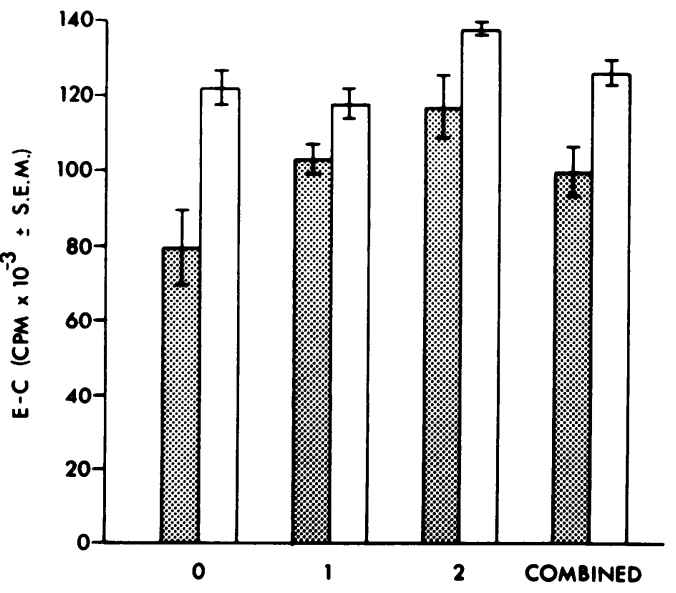

NUMBER OF INFECTIONS

FIG. 4. In vitro lymphocyte proliferation in re. sponse to mitogens, using unseparated lymph node cells (clear bars) or nonadherent cells after nylon wool separation (stippled bars) taken from uninfected mice (0) or mice infected once (1) or twice (2) cutaneously with $C$. albicans 7 days before testing.
LPS, retained their capacity to proliferate in the presence of C. albicans antigens (Fig. 5). Although counts for nonadherent cells were consistantly lower than for unseparated cells, these differences were not significantly different $(P<$ 0.05 ). Similar studies were performed 14 days after one or two cutaneous inoculations with viable $C$. albicans, and the same patterns were observed.

Anti-Thy 1.2 treatment of unseparated lymph node cells completely abolished the response of lymphocytes from infected animals to Candida antigens and reduced the PHA response by approximately $95 \%$, whereas mock anti-theta treatment had no effect (Table 3). Lymphocytes from uninfected mice, as has always been the case, were unreactive in the presence of Candida antigens regardless of the treatment. The data presented in Table 4 again show that anti-Thy 1.2 abolished the response to all Candida antigens and lowered the PHA response without affecting the LPS response. Treatment with anti-immunoglobulin serum did not abolish antigen responses but did reduce them by about $50 \%$ when compared with normal rabbit serumtreated cells and had no effect on the PHA response but did significantly lower LPS counts. It would appear, then, that although anti-immunoglobulin treatment affected responses to antigens, theta-bearing lymphocytes are the primary cells proliferating in response to Candida antigens in vitro.

\section{DISCUSSION}

We have demonstrated the usefulness of several extracts of C. albicans (GP, ppt-HEX, and SCS) in detecting cellular immune responses in sensitized animals by using an in vitro assay. Both GP and ppt-HEX had been shown to be effective in vivo previously, but SCS was not suitable for in vivo testing (9) even though it was useful in the in vitro studies described herein. Moreover, we have shown in these studies that sensitivity to GP could be passively transferred with PEC, and further, that the passive transfer of delayed hypersensitivity to pptHEX, reported previously (9), was dependent upon viable T-lymphocytes. The in vitro lymphocyte responses to all three antigens were shown to be T-dependent as well, in that antiThy 1.2 treatment of lymphocyte suspensions resulted in the abrogation of responsiveness of lymphoid cells to the Candida antigens and PHA.

We have also presented some preliminary evidence to suggest that when used in the lymphocyte stimulation assay, the ppt-HEX antigen derived from $C$. albicans is specific for $C$. albi- 


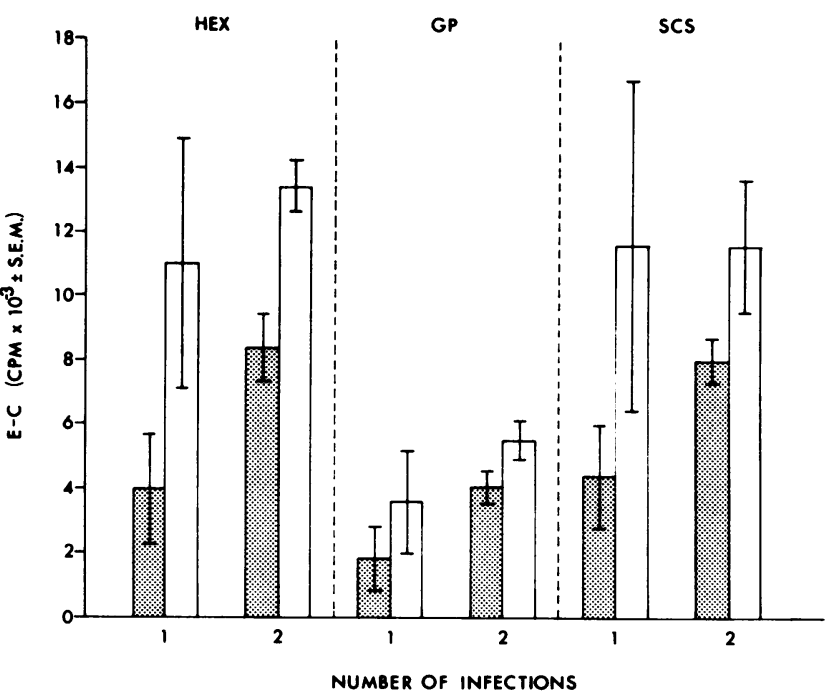

Fig. 5. In vitro lymphocyte proliferation to three $C$. albicans antigens, using unseparated lymph node cells (clear bars) or nonadherent lymphocytes after nylon wool separation (stippled bars) taken from uninfected mice (0) or mice infected once (1) or twice (2) cutaneously with viable C. albicans 7 days before testing.

TABLE 3. Effect of anti-Thy 1.2 serum or mock anti-theta serum on antigen and mitogen responses of unseparated lymph node cells from uninfected mice or mice infected a second time cutaneously with $C$. albicans 7 days before assay

\begin{tabular}{|c|c|c|c|c|c|c|c|c|c|}
\hline \multirow{3}{*}{$\begin{array}{l}\text { Antigen or } \\
\text { Mitogen }\end{array}$} & \multirow{3}{*}{$\begin{array}{c}\text { Concn } \\
(\mu \mathrm{g} / \mathrm{well})\end{array}$} & \multicolumn{4}{|c|}{ Uninfected } & \multicolumn{4}{|c|}{ Infected } \\
\hline & & \multicolumn{2}{|l|}{ Mock } & \multicolumn{2}{|c|}{ Thy 1.2} & \multicolumn{2}{|l|}{ Mock } & \multicolumn{2}{|c|}{ Thy 1.2} \\
\hline & & $\mathrm{cpm}^{a}$ & $\mathrm{E} / \mathrm{C}^{b}$ & cpm & $\mathrm{E} / \mathrm{C}$ & cpm & $\mathrm{E} / \mathrm{C}$ & $\mathrm{cpm}$ & $\mathrm{E} / \mathrm{C}$ \\
\hline Antigen & & & & & & & & & \\
\hline None & & $291(81)$ & 1.0 & $119(16)$ & 1.0 & $249(8)$ & 1.0 & $186(14)$ & 1.0 \\
\hline ppt-HEX & 20 & $276(53)$ & 0.9 & 137 (15) & 1.2 & $3,660(2,319)$ & 14.7 & $186(10)^{c}$ & 1.0 \\
\hline GP & 200 & $218(49)$ & 0.7 & $136(14)$ & 1.2 & $3,446(2,066)$ & 13.8 & $155(4)^{c}$ & 0.8 \\
\hline SCS & 100 & $343(75)$ & 1.2 & $144(18)$ & 1.3 & $7,608(4,439)$ & 30.6 & $204(41)^{c}$ & 1.1 \\
\hline Mitogen & & & & & & & & & \\
\hline $\begin{array}{l}\text { None } \\
\text { PHA }\end{array}$ & & $\begin{array}{c}287(80) \\
103\end{array}$ & $\begin{array}{r}1.0 \\
359 ?\end{array}$ & $134(6)^{c}$ & 1.0 & $320(31)$ & 1.0 & $147(27)^{c}$ & 1.0 \\
\hline LPS & $\begin{array}{r}0.00 \\
50.00\end{array}$ & $\begin{array}{c}103,081(1,783) \\
2,509(581)\end{array}$ & $\begin{array}{r}359.2 \\
8.7\end{array}$ & $1,777(188)^{2}$ & $\begin{array}{r}13.3 \\
37\end{array}$ & 113,787 (6,710) & 355.6 & $2,746(599)^{c}$ & 18.7 \\
\hline & & & & & & & & & \\
\hline
\end{tabular}

${ }^{a}$ Mean of three pools, each pool consisting of five mice (standard error of the mean).

${ }^{b}$ Ratio of experimental to control.

${ }^{c}$ Value significantly decreased $(P<0.05)$ compared with control value.

cans and closely related Candida species only. The ppt-HEX preparation of $C$. tropicalis, a Candida species known to be related to $C$. albicans, was the only extract to stimulate the cells taken from animals sensitized to $C$. albicans. Obviously, definitive data have not been presented to draw firm conclusions, since the possibility exists that cross-reacting components from the other organisms were not removed by the extraction procedure, nor were a large battery of strains tested. Moreover, lymphocytes from animals sensitized with heterologous yeasts and then tested with the $C$. albicans extracts may be a more sensitive indication of the pres- ence of cross-reacting components. Nevertheless, the fact remains that ppt-HEX from $C$. guillermondii, a Candida species not closely related to $C$. albicans, and ppt-HEX extracts from $H$. capsulatum and $B$. dermatitidis were not stimulatory.

The studies of in vitro lymphocyte stimulation with Candida antigens appearing in the literature have involved largely human peripheral blood lymphocytes $(1,2,10,11,12,15-17,29$, $31)$. The antigens used were primarily commercial preparations that had been dialyzed or diluted to eliminate the effects of preservatives. In our hands, the commercial antigens have not 
TABLE 4. Effect of anti-Thy 1.2 serum, mock anti-theta serum, normal rabbit serum (NRS), or rabbit antimouse immunoglobulin (Ig) serum and complement on antigen and mitogen responses of lymph node cells from mice infected twice cutaneously with C. albicans ${ }^{a}$

\begin{tabular}{l|c|c|r|c|r|r|r|r|r}
\hline \multirow{2}{*}{$\begin{array}{c}\text { Antigen or } \\
\text { Mitogen }\end{array}$} & $\begin{array}{c}\text { Concn }(\mu \mathrm{g} / \\
\text { well) }\end{array}$ & \multicolumn{2}{|c|}{ Mock } & \multicolumn{2}{c|}{ anti-Thy 1.2} & \multicolumn{2}{c|}{ NRS } & \multicolumn{2}{c}{ anti-Ig } \\
\cline { 3 - 9 } $\mathrm{cpm}^{b}$ & $\mathrm{E} / \mathrm{C}^{c}$ & $\mathrm{cpm}$ & $\mathrm{E} / \mathrm{C}$ & $\mathrm{cpm}$ & $\mathrm{E} / \mathrm{C}$ & $\mathrm{cpm}$ & $\mathrm{E} / \mathrm{C}$ \\
\hline $\begin{array}{l}\text { Antigen } \\
\text { None }\end{array}$ & & $147(17)$ & 1.0 & $142(35)$ & 1.0 & $169(34)$ & 1.0 & $124(17)$ & 1.0 \\
ppt-HEX & 20 & $1,380(183)$ & 9.4 & $304(116)^{d}$ & 2.1 & $4,634(157)$ & 27.4 & $2,129(200)^{d}$ & 17.2 \\
GP & 200 & $482(83)$ & 3.3 & $122(9)^{d}$ & 0.9 & $2,372(196)$ & 14.0 & $1,040(52)^{d}$ & 8.4 \\
SCS & 100 & $1,940(105)$ & 13.2 & $210(39)^{d}$ & 1.5 & $7,231(545)$ & 42.8 & $3,141(131)^{d}$ & 25.3 \\
Mitogen & & & & & & & & & \\
None & & $153(2)$ & 1.0 & $153(2)$ & 1.0 & $187(9)$ & 1.0 & $159(6)$ & 1.0 \\
PHA & 0.05 & $57,806(1,634)$ & 377.8 & $26,186(1,274)^{d}$ & 171.2 & $53,145(1,050)$ & 284.2 & $63,779(836)$ & 401.0 \\
LPS & 50.00 & $550(61)$ & 3.6 & $697(31)$ & 4.5 & $1,188(82)$ & 6.4 & $322(51)^{d}$ & 2.0 \\
\hline
\end{tabular}

${ }^{a}$ Data from a single pool of lymph node cells from 15 mice.

${ }^{b}$ Mean (standard error of the mean).

${ }^{c}$ Ratio of experimental to control.

${ }^{d}$ Value significantly decreased $(P<0.05)$ compared with control value.

been useful either in vivo or in vitro. Some investigators using commercial antigens, e.g., Bice et al. (2) and Ferguson et al. (10), found a quantitative relationship between lymphocyte stimulation and skin test reactions. Bice et al. (2), however, used two different extracts, one for skin testing and another for the in vitro assays. In the animal experiments reported herein, only qualitatitive relationships between in vivo and in vitro assays were noted. For example, the footpad response to ppt-HEX and GP decreased significantly between 7 and 14 days after a second cutaneous inoculation with viable $C$. albicans, but the level of lymphocyte stimulation observed in vitro did not decrease during that time.

Frisk et al. (12) and Foroozanfar et al. (11) are among the few investigators who have used antigens other than those commercially available to stimulate human lymphocytes. Frisk et al. (12), using whole homogenized C. albicans cytoplasmic substances, or a cell wall glycoprotein analogous to the one used here, found that glycoprotein stimulated human peripheral lymphocytes to the greatest degree. Foroozanfar et al. (11), using a preparation similar to our SCS, obtained positive stimulation with lymphocytes from $100 \%$ of the normal subjects tested.

Studies involving in vitro lymphocyte stimulation with Candida antigens in animal models of disease have been limited. Frisk et al. (13), however, working with guinea pigs, used an unmodified culture filtrate of $C$. albicans to stimulate cells and found it to be superior to Dermatophytin O. Additionally, Rogers and Balish (27), working with mice infected systemically and using a formolized whole yeast suspension and PHA, reported suppression of stimulation with spleen cells. In the model used in our studies, i.e., the cutaneous inoculation of viable Candida, suppression of the in vitro response to either soluble antigens of $C$. albicans or mitogens did not occur. There have been several other reports of lymphocyte stimulation with $C$. albicans antigens in which killed yeasts $(27,28)$, cytoplasmic substances $(11,30)$, or particulate material from disrupted yeasts $(12,24)$ have been used as antigen, but the stimulation indices were in general small and the use of particulate antigens may be undesirable because of the possibility that they might be more mitogenic to Blymphocytes, as is particulate PHA or concanavalin $A$.

Studies by others involving the transfer of delayed hypersensitivity to Candida antigens have also been limited. Pearsall et al. (23) found that a mixture of spleen and lymph node cells from immune mice transferred delayed hypersensitivity to an unspecified commercial C. albicans antigen from Hollister-Stier. Rifkind et al. (24) used spleen cells from mice immunized with a sonic extract of $C$. albicans to passively transfer footpad reactivity. They also reported that ribonucleic acid extracted from immune cells converted normal spleen cells to an immune state capable of transferring hypersensitivity $(25,26)$. We have been largely unsuccessful in transferring hypersensitivity with spleen or lymph node cells, but have been successful with PEC as presented here and elsewhere (9). Our studies were patterned after those of investigators who were successful in transferring cellular immunity with PEC in different animal models $(4,20,22,30)$.

In summary, cutaneous inoculation of mice with viable $C$. albicans blastospores induced a strong delayed-type hypersensitivity to a cell wall glycoprotein (GP) and a membrane protein (ppt-HEX) from C. albicans which is apparently mediated by T-lymphocytes. Lymph node cells from these cutaneously infected mice responded to three homologous antigens and to ppt-HEX 
derived from a closely related Candida species, but did not respond to ppt-HEX from several fungi belonging to different genera. This in vitro response appeared to be dependent upon T-lymphocytes as well, with responses by B-lymphocytes also present in unseparated lymph node cell populations.

\section{ACKNOWLEDGMENTS}

This investigation was supported by Public Health Service grants AI-12308, AI-00003, and AI-01752 from the National Institute of Allergy and Infectious Diseases. S.A.M. was a trainee in medical mycology.

\section{LITERATURE CITED}

1. Alford, R. H. 1973. Transformation of lymphocytes of normal and hospitalized adults by Candida albicans extract. Proc. Soc. Exp. Biol. Med. 144:826-829.

2. Bice, D. E., M. Lopez, H. Rothschild, and J. Salvaggio. 1974. Comparison of Candida-delayed hypersensitivity skin test size with lymphocyte transformation, migration inhibitory factor production and antibody titer. Int. Arch. Allergy 47:54-62.

3. Brummer, E., T. W. Vris, and H. S. Lawrence. 1977. A microculture system for the measurement of antigen induced murine lymphocyte proliferation: advantages of $5 \%$ horse serum and $5 \times 10^{-5} \mathrm{M}$ mercaptoethanol. J. Immunol. Methods 17:319-327.

4. Chase, M. W. 1945. The cellular transfer of cutaneous hypersensitivity to tuberculin. Proc. Soc. Exp. Biol. Med. 59:134-135.

5. Cohen, A., and M. Schlesinger. 1970. Absorption of guinea pig serum with agar. A method for elimination of its cytotoxicity for murine thymus cells. Transplantation 10:130-132.

6. Cohen, R., F. J. Roth, R. Delgado, D. G. Ahearn, and M. H. Kalser. 1969. Fungal flora of the normal human small and large intestine. N. Engl. J. Med. 280:638-641.

7. Dixon, W. J., and M. B. Brown. 1977. BMDP-77. University of California Press, Berkeley.

8. Domer, J. E. 1976. In vivo and in vitro cellular responses to cytoplasmic and cell wall antigens of Histoplasma capsulatum in artificially immunized or infected guinea pigs. Infect. Immun. 13:790-799.

9. Domer, J. E., and S. A. Moser. 1978. Experimental murine candidiasis: cell-mediated immunity after cutaneous challenge. Infect. Immun. 20:88-98.

10. Ferguson, A. C., H. E. Kershnar, W. K. Collin, and E. R. Stiehm. 1977. Correlation of cutaneous hypersensitivity with lymphocyte response to Candida albicans. Am. J. Clin. Pathol. 68:499-504.

11. Foroozanfar, N., M. Yamamura, and J. R. Hobbs. 1974. Standardization of lymphocyte transformation to Candida immunogen. Clin. Exp. Immunol. 16:301-310.

12. Frisk, A., L.-V. von Stedingk, and J. Wasserman. 1974. Lymphocyte stimulation in Candida albicans infections. Sabouraudia 12:87-94.

13. Frisk, A., and J. Wasserman. 1969. Lymphocyte stimulation with Candida albicans antigens. Antonie von Leeuwenhoek 35(Suppl.):E13.

14. Giger, D. K., J. E. Domer, and J. T. McQuitty, Jr. 1978. Experimental murine candidiasis: pathologica and immune responses to cutaneous inoculation with
Candida albicans. Infect. Immun. 19:499-509.

15. Hanifin, J. M., L. F. Ray, and W. C. Lobitz, Jr. 1974. Immunological reactivity in dermatophytosis. Br. J. Dermatol. 90:1-8.

16. Hassett, A. M., R. J. Woods, I. J. Temperley, and G. M. Mullins. 1977. Cell mediated immunity to recall antigens in vivo and in vitro. Irish J. Med. Sci. 146: 167-174.

17. Helander, I. 1978. The lymphocyte transformation test in dermatophytosis. Mykosen 21:71-80.

18. Julius, M. H., E. Simpson, and L. A. Herzenberg. 1973. A rapid method for the isolation of functional thymus-derived murine lymphocytes. Eur. J. Immunol. 3:645-649.

19. Korn, E. D., and D. H. Northcote. 1960. Physical and chemical properties of polysaccharides and glycoproteins of the yeast-cell wall. Biochem. J. 75:12-17.

20. Landsteiner, K., and M. W. Chase. 1942. Experiments on transfer of cutaneous sensitivity to simple compounds. Proc. Soc. Exp. Biol. Med. 49:688-690.

21. Lowry, O. H., N. J. Rosebrough, A. L. Farr, and R. J. Randall. 1951. Protein measurement with the Folin phenol reagent. J. Biol. Chem. 193:265-275.

22. North, R. J., and G. Spitalny. 1974. Inflammatory lymphocytes in cell-mediated antibacterial immunity: factors governing the accumulation of mediator $\mathrm{T}$ cells in peritoneal exudates. Infect. Immun. 10:489-498.

23. Pearsall, N. N., B. L. Adams, and R. Bunni. 1978 Immunologic responses to Candida albicans. III. Effects of passive transfer of lymphoid cells or serum on murine candidiasis. J. Immunol. 120:1176-1180.

24. Rifkind, D., J. A. Frey, J. R. Davis, E. A. Petersen, and M. Dinowitz. 1976. Delayed hypersensitivity to fungal antigens in mice. I. Use of the intradermal skin and footpad swelling tests as assays of active and passive sensitization. J. Infect. Dis. 133:50-56.

25. Rifkind, D., J. A. Frey, E. A. Petersen, and M. Dinowitz. 1976. Delayed hypersensitivity to fungal antigens in mice. II. Molecular classes in immunogenic RNA extracts that transfer delayed hypersensitivity. J. Infect. Dis. 133:523-532.

26. Rifkind, D., J. A. Frey, E. A. Petersen, and M. Dinowitz. 1976. Delayed hypersensitivity to fungal antigens in mice. III. Characterization of the active component in immunogenic RNA extracts. J. Infect. Dis. 133:533537.

27. Rogers, T. J., and E. Balish. 1978. Suppression of lymphocyte blastogenesis by Candida albicans. Clin. Immunol. Immunopathol. 10:298-305.

28. Rogers, T. J., and E. Balish. 1978. Effect of systemic candidiasis on blastogenesis of lymphocytes from germfree and conventional rats. Infect. Immun. 20:142-150.

29. Shannon, D. C., G. Johnson, F. S. Rosen, and K. F. Austen. 1966. Cellular reactivity to Candida albicans antigen. N. Engl. J. Med. 275:690-693.

30. Sohnle, P. G., M. M. Frank, and C. H. Kirkpatrick. 1976. Mechanisms involved in elimination of organisms from experimental cutaneous Candida albicans infections in guinea pigs. J. Immunol. 117:523-530.

31. Steele, R. W., P. B. Cannady, Jr., W. L. Moore, Jr., and L. O. Gentry. 1976. Skin test and blastogenic responses to Sporotrichum schenckii. J. Clin. Invest. 57:156-160

32. Winer, B. J. 1962. Statistical principles in experimental design, chapter 7. McGraw-Hill Book Co., New York. 